\title{
Movimentos de subjetivação da criança na aquisição da escrita: uma discussão voltada às rasuras
}

\section{Subjectivation movements of children in writing acquisition: a discussion focused on erasures}

\section{Movimientos de subjetivación de los niños en la adquisición de escritura: una discusión centrada en los borrados}

(iD) Letícia do Nascimento Schavarem
Universidade Estadual do Centro-Oeste (UNICENTRO), Irati, Paraná, Brasil. Email: leticiaschavaren@hotmail.com

iD@Pascoalina Bailon de Oliveira Saleh Universidade Estadual de Ponta Grossa (UEPG), Ponta Grossa, Paraná, Brasil. Email: pbosaleh@gmail.com

Resumo: Neste estudo propomos uma discussão sobre as rasuras presentes nos textos de crianças que se encontram em aquisição da escrita e apresentam dificuldades nesse processo, sendo, por isso, encaminhadas à clínica fonoaudiológica e/ou inseridas em turmas de contraturno. A perspectiva que sustenta esta discussão é o Interacionismo em aquisição da linguagem, proposto por De Lemos (1992, 1999, 2002). O objetivo do estudo é investigar os movimentos de subjetivação indiciados pela presença de rasuras na elaboração de textos produzidos por essas crianças. A análise aponta dois movimentos da criança: de independência da escrita do Outro e de relativa dependência do texto escrito que vem do Outro.

Palavras-chave: Subjetividade. Interacionismo. Rasura. Aquisição. Escrita.

\footnotetext{
1 Este artigo baseia-se na Dissertação de Mestrado intitulada "Movimentos de subjetivação da criança na aquisição da escrita: uma discussão voltada às rasuras", defendida no Programa de Pós-Graduação em Estudos da Linguagem, sob orientação da Profa. Dra. Pascoalina Bailon de Oliveira Saleh.
} 


\begin{abstract}
In this study, we propose a discussion about the erasures present in the texts of children who are in acquisition of writing and have difficulties in this process, being, therefore, referred to the speech therapy clinic and / or inserted in night classes. The perspective that supports this discussion refers to Interactionism in language acquisition, proposed by De Lemos (1992 and others). The aim of the study is to investigate the movements of subjectification indicated by the presence of erasures in the elaboration of texts produced by these children. The analysis points to two movements of the child: of independence from the writing of the Other and of relative dependence on the written text that comes from the Other.
\end{abstract}

Keywords: Subjectivity. Interactionism. Erasure. Acquisition. Writing.

Resumen: En este estudio proponemos una discusión sobre las tachaduras presentes en los textos de niños que están en adquisición de escritura y tienen dificultades en este proceso, siendo, por tanto, referidos a la clínica logopédica y / o insertados en clases nocturnas. La perspectiva que sustenta esta discusión se refiere al interaccionismo en la adquisición del lenguaje, propuesto por De Lemos (1992 y otros). El objetivo del estudio es investigar los movimientos de subjetivación que indica la presencia de tachaduras en la elaboración de textos producidos por estos niños. El análisis apunta a dos movimientos del niño: de independencia de la escritura del Otro y de dependencia relativa del texto escrito que proviene del Otro.

Palabras clave: Subjetividad. Interaccionismo. Borrado. Adquisición. Escritura.

Submetido em 12 de dezembro de 2019. Aceito em 22 de setembro de 2020.

Publicado em 16 de novembro de 2020. 
Movimentos de subjetivação da criança na aquisição da escrita: uma discussão... Letícia do Nascimento Schavarem • Pascoalina Bailon de Oliveira Saleh

\section{Introdução}

Neste trabalho abordamos questões referentes à aquisição da escrita, com base na abordagem teórica Interacionista em aquisição da linguagem, proposta por De Lemos (1992, 1995, 1999, 2002, 2006). Fundamentada por um ponto de vista que inclui a Linguística estruturalista, bem como a Psicanálise lacaniana, a pesquisadora critica a noção de desenvolvimento, dominante na área da aquisição. Para isso, baseia-se em reflexões em que o erro na fala da criança ocupa lugar central e é interpretado em termos da posição da criança em relação à fala do Outro² e à sua própria fala.

Levando em consideração esse aporte teórico, as discussões acerca da aquisição da escrita que dão sustentação a este trabalho têm em vista a análise de movimentos subjetivos da criança no momento em que esta realiza a rasura. De acordo com Cavalcante (2010), as rasuras presentes na escrita nos permitem investigar e discutir as relações do sujeito com a linguagem, buscando compreender o funcionamento e a ocorrência dessas rasuras, tomadas como marcas de um conflito do sujeito com sua escrita. Nesse sentido, nosso foco volta-se às rasuras presentes nos textos de crianças que se encontram na aquisição da escrita e, especificamente, de sujeitos que apresentam dificuldades nesse processo, que, por vezes, são encaminhados à clínica fonoaudiológica e/ou inseridos em turmas de contraturno ${ }^{3}$, como é o caso dos sujeitos da pesquisa.

Consideramos importante a realização desta discussão visto que envolve crianças que apresentam dificuldades na aquisição da

\footnotetext{
2 No decorrer do nosso trabalho, utilizamos o termo Outro com O maiúsculo por se tratar, como aponta Lacan (2008), do Outro primordial na constituição do sujeito. Conforme o autor, "o sujeito nasce no que, no campo do Outro, surge o significante" (LACAN, 2008, p. 194), significante este entendido como o que representa o sujeito para um outro significante. De Lemos (2002) também faz referência ao Outro, como veremos mais adiante, tido como fundamental para o sujeito na aquisição da linguagem.

3 Ao utilizar o termo contraturno, estamos nos referindo a turmas de atividades complementares ao ensino, compostas por crianças com dificuldades na aprendizagem. De acordo com as Diretrizes Curriculares Nacionais Gerais de Educação Básica (2013), por meio de diferentes tipos de avaliações escolares que buscam analisar o sucesso de cada aluno em seu desenvolvimento escolar, há a possibilidade de determinar quais alunos necessitam de um atendimento complementar que vise a enfrentar as dificuldades por eles apresentadas. Esse atendimento pode ser oferecido, conforme apontam as Diretrizes, no horário de aula ou em período de contraturno. Portanto, "contraturno" aparecerá, no decorrer do nosso trabalho, no sentido de indicar que as crianças participam de uma turma de "reforço escolar".
} 
Movimentos de subjetivação da criança na aquisição da escrita: uma discussão... Letícia do Nascimento Schavarem • Pascoalina Bailon de Oliveira Saleh

escrita e que, frequentemente, são "rotuladas" pelo "fracasso escolar", tendo "problemas de leitura e escrita" e ficando, por vezes, invisíveis entre as práticas escolares em que o foco volta-se para seus erros e suas dificuldades, desconsiderando-as como sujeitos dessas práticas.

Destacamos que o termo "fracasso escolar", apontado acima, não está associado às rasuras, pois as entendemos como parte da aquisição da escrita. Nossa compreensão sobre o fracasso escolar se aproxima do que aborda, por exemplo, Pires (2011). De acordo com a autora, o fracasso indica que existe resistência aos métodos escolares, trazendo à tona sujeitos que não se "comportam" como o esperado, não apresentando suas escritas de acordo com aquilo que os métodos escolares preveem e esperam. Isto é, essas crianças que parecem tender ao fracasso acabam apresentando descolamento e mobilidade em sua escrita, como destaca a pesquisadora e, por isso, se torna de extrema importância que esses sujeitos sejam vistos a partir de suas singularidades e subjetividades nesse processo.

Uma vez que a discussão será desenvolvida a partir de uma formação da fonoaudiologia, procuraremos estabelecer contribuições referentes à clínica fonoaudiológica, para onde casos com queixas de leitura e escrita são encaminhados frequentemente, auxiliando na reflexão sobre os $\operatorname{casos}^{4}$ que demandariam atendimento fonoaudiológico.

Portanto, acreditamos que a análise e a discussão dos dados nos permitirão avançar sobre a compreensão da rasura na escrita infantil. Para isso, partiremos dos seguintes questionamentos: 0 que as rasuras dizem a respeito da relação dessas crianças com a escrita? Quais os movimentos subjetivos estão em questão? Há diferenças entre os movimentos das crianças que se mantêm presas ao texto do Outro e aquelas que não se mantêm? O que isso diz

\footnotetext{
4 Na experiência clínica, nos deparamos com uma diversidade de casos clínicos envolvendo impasses no decorrer da aquisição da escrita. Notamos, por exemplo, que, em grande maioria, são casos encaminhados pela escola por considerarem que a criança está enfrentando alguma dificuldade no seu processo e, por isso, demanda um acompanhamento externo à escola, como o ofertado pelo fonoaudiólogo. Vemos, muitas vezes, nesses casos, que essas crianças chegam à clínica fonoaudiológica sob o efeito da leitura e do lugar que a escola as coloca, ou seja, o de "fracasso escolar", como abordaremos neste estudo.
} 
Movimentos de subjetivação da criança na aquisição da escrita: uma discussão... Letícia do Nascimento Schavarem • Pascoalina Bailon de Oliveira Saleh

de suas subjetividades e singularidades no processo? Suas rasuras provocam os mesmos efeitos?

Norteado por tais questionamentos, o presente estudo tem como objetivo investigar os movimentos de subjetivação indiciados pela presença de rasuras na elaboração de textos produzidos por crianças em aquisição da escrita, inseridas em turmas de contraturno e/ou encaminhadas para a clínica fonoaudiológica. Para isso, estabelecemos os seguintes objetivos específicos: (i) discutir o movimento do sujeito durante a produção de textos; (ii) discutir o movimento do sujeito implicado na rasura; (iii) verificar as singularidades de movimentos entre o sujeito que se mantém em uma relação de dependência do texto do Outro e aquele que não se mantém.

Diante do exposto, trazemos a seguir os pontos fundamentais da construção teórica de Cláudia de Lemos em sua leitura do processo de aquisição, bem como de autores que realizam um importante desdobramento dessa perspectiva no campo da aquisição da escrita.

\section{O Interacionismo de Cláudia de Lemos: um reconheci- mento da "ordem própria da língua"}

De Lemos (2006) faz uma crítica à visão de desenvolvimento linguístico que estabelece estágios de desenvolvimento a partir de tentativas de realizar a descrição da fala da criança, definindo-se, pois, a aquisição da linguagem como processo de aprendizagem ou de construção de conhecimento. De acordo com a autora, esse viés desconsidera a heterogeneidade e a imprevisibilidade da língua, observadas a partir de expressões corretas e incorretas na fala de uma mesma criança, em uma mesma sessão fonoaudiológica.

Portanto, a mudança que ocorre na fala da criança se dará a partir de três posições, considerando uma estrutura estabelecida 
Movimentos de subjetivação da criança na aquisição da escrita: uma discussão... Letícia do Nascimento Schavarem • Pascoalina Bailon de Oliveira Saleh

entre Outro-criança-língua, em que o Outro é tido como instância de língua já constituída, que dará sentido à fala/escrita da criança por meio de sua interpretação e de seus significantes, possibilitando que o sujeito seja capturado pela língua; a criança é aqui significada como sujeito falante, cindido entre consciente e inconsciente, e a língua é considerada em seu funcionamento como imprevisível em razão do jogo significante, possibilitando a relação língua-sujeito/criança (DE LEMOS, 2002).

Quanto às posições referentes ao processo de mudança da fala da criança, elas se estabelecem da seguinte forma: na primeira posição, o sujeito se encontra alienado à fala do Outro, incorporando fragmentos dessa fala; na segunda posição, o sujeito é marcado por contrastes entre "erros" e acertos, porém não é afetado pelos seus "erros", sendo impermeável à correção; já a terceira posição está relacionada a correções, hesitações, pausas e reformulações, pois nela a criança escuta sua própria fala, sendo afetada pelo estranhamento do Outro em relação à sua fala e pelas suas próprias produções. Nessa posição a linguagem da criança se aproxima da língua constituída, pois transparece uma relação mais estável da criança com a língua (DE LEMOS, 2002).

A partir disso, De Lemos (2002) reconhece na língua a função de captura, pois esta (a língua),

considerada sua anterioridade lógica relativamente ao sujeito, o precede e, considerada em seu funcionamento simbólico, poder-se-ia inverter a relação sujeito objeto, conceber a criança como capturada por um funcionamento linguístico discursivo que não só a significa como lhe permite significar outra coisa, para além do que a significou (DE LEMOS, 2002, p. 55).

Portanto, a língua é inscrita na criança, isto é, não é a criança que se apropria da linguagem e sim a língua e o jogo simbólico que a capturam (DE LEMOS, 2002). 
Movimentos de subjetivação da criança na aquisição da escrita: uma discussão... Letícia do Nascimento Schavarem • Pascoalina Bailon de Oliveira Saleh

Conforme a autora, a noção de "escuta" também assume um papel importante nesse processo. Andrade (2003) aponta para a noção de escuta, interpretando-a, a partir de Cláudia de Lemos, como "efeito da estruturação do sujeito pela linguagem" (ANDRADE, 2003, p. 27), incluindo o linguístico na interpretação dos problemas na fala. Assim, a escuta estabelece uma relação da criança com a fala e o funcionamento da língua, o que abre espaço para a presença do sujeito, implicando uma posição subjetiva. Portanto, dizer que há escuta do sujeito para a fala significa dizer que esse sujeito "sustenta uma fala não-coincidente com a do Outro" (ANDRADE, 2003, p. 90).

O Interacionismo de Cláudia de Lemos possibilitou que autores como Borges (2006; 2010); Borges; Silva e Loures (2017); Lier-DeVitto e Andrade (2011a); Bosco (2005); Capristano (2007; 2013), Aspilicueta (2014), entre outros, realizassem importantes discussões acerca da aquisição da escrita, que embasam a análise dos nossos dados.

Borges (2006) afirma que os elementos observados em escrita de crianças não são considerados como impressões perceptuais e processos cognitivos que agem sobre unidades da língua já constituída. Trata-se da "criança sendo escrita pelo Outro", de um sujeito capturado pela linguagem escrita, e não a escrita tida como um objeto apreendido pela criança. Além disso, ela destaca que cada sujeito é afetado por significantes que decorrem de sua própria relação com o Outro e, portanto, a produção de cada uma é considerada singular.

Em outro estudo, Borges, Silva e Loures (2017) discutem as questões envolvidas na alfabetização, fazendo contrapontos importantes com perspectivas teóricas que desconsideram o sujeito, além de teorias e práticas pedagógicas em que a escrita é considerada como representação da fala. De acordo com Borges (2010) e Borges, Silva e Loures (2017), ao considerar a escrita como representação gráfica da fala, pressupõe-se a aquisição da escrita como construção que se dá a partir dessa relação representacionista, envolvendo situações de ensino-aprendizagem tidas como facilita- 
Movimentos de subjetivação da criança na aquisição da escrita: uma discussão... Letícia do Nascimento Schavarem • Pascoalina Bailon de Oliveira Saleh

doras de operações cognitivas. Dessa forma, as autoras sustentam que se faz necessária a introdução do sujeito no lugar do cognitivo, tornando-o responsável pelas suas questões/queixas, pois as dificuldades encontradas pela criança na aquisição da escrita não são (e não podem ser) explicadas sempre por causas orgânicas, intelectuais e neurológicas.

Borges (2010) refere-se ainda à necessidade de considerar o funcionamento e a sistematicidade da língua para que se possa sair dessa noção de representação, que se sustenta em concepções racionalistas. Como destaca a autora, isso foi realizado nos trabalhos de Cláudia de Lemos voltados à aquisição da linguagem oral, influenciando estudos sobre a alfabetização. Nesse sentido, a noção de representação passa por um processo de ressignificação com base nos conceitos da Psicanálise. Entende-se que a escrita da criança envolve transições pelas representações que vêm do Outro, inseridas na ordem discursiva, permitindo que sejam produzidas representações tanto em relação ao que é possível como também ao que não é possível na escrita dada como constituída. A alfabetização, portanto, conforme Borges (2010), demanda uma representação simbólica, pois o sujeito representa a escrita por meio de situações que envolvem leitura e escrita de textos.

Interpretamos essa ressignificação e diferenciação da seguinte forma: a escrita como representação da oralidade significa que há, aí, a representação por meio de códigos (da fala na escrita), considerando que tudo aquilo que é falado pode ser representado da mesma forma na escrita, porém a escrita possui um funcionamento diferente da fala. Quanto à representação simbólica, a partir do exposto acima, a compreendemos como configuração/ funcionamento da escrita a partir da própria escrita, o que envolve o Outro enquanto escrita já constituída, em suas diversas formas. Portanto, assim como Borges (2010), consideramos a heterogeneidade constitutiva da escrita (e da fala).

Lier-DeVitto e Andrade (2011) buscam viabilizar uma abordagem particular no que se refere à relação "criança-escrita ou criança-fala-escrita", pois 
Movimentos de subjetivação da criança na aquisição da escrita: uma discussão... Letícia do Nascimento Schavarem • Pascoalina Bailon de Oliveira Saleh

\begin{abstract}
se a transparência de unidades da matéria acústica (que chega à criança como um fluxo contínuo) não é questionada, menos ainda o é a transparência da matéria gráfica (que a criança recebe numa pauta demarcada: com intervalos, segmentos e sinais estáveis). A escrita é erigida, nesse contexto, como representação de segunda ordem, ou seja, representação gráfica de uma representação sonora do mundo (LIER-DEVITTO; ANDRADE, 2011, p. 99 - grifos da autora).
\end{abstract}

Portanto, as autoras propõem um olhar alternativo em relação às escritas da criança, considerando a implicação do "jogo significante" a partir da proposta saussuriana. Assim, realizam uma análise de textos iniciais, a partir dos quais é possível "recolher movimentos e impasses da relação criança-linguagem" (LIER-DEVITTO; ANDRADE, 2011, p. 111).

Outra autora que discute a aquisição da escrita é Bosco (2005), que faz análise de "assinaturas" e textos compostos pelas letras do nome da criança. Seu foco é voltado ao papel que o nome próprio possui na relação da criança com a escrita, indicando que a escrita do nome, em sua função de assinatura, marca lugar de investimento do sujeito, resultando da relação da criança com discursos tanto orais como escritos, que vêm do Outro. Dessa forma, Bosco destaca que as primeiras escritas da criança não apresentam letras aleatórias, pois surgem do nome próprio, que insere a criança na ordem da linguagem, designando sua inscrição simbólica.

De acordo com Bosco (2005), é necessário um apagamento do valor figurativo da propriedade das letras do nome, pois, por meio da linguagem, as letras se tornarão elementos da escrita, ou seja, poderão escrever outros textos. Esses textos, nos quais as letras do nome próprio marcam presença, são “cifrados, marcados pelo não-sentido, mas nos quais se podem produzir, pela antecipação do outro, efeitos de sentido, de uma unidade na leitura, ainda que de completude imaginária" (BOSCO, 2005, p. 168). 
Movimentos de subjetivação da criança na aquisição da escrita: uma discussão... Letícia do Nascimento Schavarem • Pascoalina Bailon de Oliveira Saleh

Portanto, as escritas analisadas pela autora "apresentam realizações gráficas constituídas por letras do nome da criança, compondo blocos que, em princípio, não se organizam da maneira como prevê a língua dita constituída, revelando uma escrita em que o não-sentido, de início, chega a se impor" (BOSCO, 2005, p. 5).

Também os estudos de Capristano (2007; 2010; 2013), elaborados no âmbito da Linguística Aplicada, mas tendo em De Lemos (2002) um importante aporte teórico, apresentam contribuições nas discussões relacionadas à aquisição da escrita. Em sua tese de doutorado, Capristano (2007) busca entender de que forma as segmentações nas escritas de crianças se modificam no decorrer do tempo, além de tentar explicar as divergências presentes entre enunciados propostos por uma mesma criança em diferentes momentos da aquisição, divergências estas que não são suportadas por uma explicação baseada na noção de desenvolvimento sucessivo e regular, colocando em oposição à ideia de que a aquisição da escrita poderia ser considerada igual para todas as crianças.

A concepção defendida por Capristano (2007), ou seja, baseada na visão Interacionista de Cláudia de Lemos, destaca, pois, a inviabilidade de se realizar uma interpretação da aquisição da escrita a partir do desenvolvimento ordenado de hipóteses elaboradas pela criança, como concebido pelo construtivismo de Ferreiro (2001), pois observa-se uma oscilação ou ausência de sequencialidade. Dessa forma, segundo a pesquisadora, a oscilação/flutuação na constituição da escrita do sujeito não poderá ser descrita em etapas lineares e sucessivas.

Com base no Interacionismo de Claudia de Lemos e de um ponto de vista enunciativo, Aspilicueta (2014) é outra autora que discute a aquisição da escrita, bem como os movimentos de enunciação de textos de crianças que apresentam dificuldades nesse processo. Seu enfoque é em relação à cópia ou repetição do texto do Outro, pois durante a coleta de dados, ao solicitar aos participantes que escrevessem sobre o que entenderam da história ou qual parte mais gostaram, as crianças acabavam deslizando para a cópia do texto. 
Movimentos de subjetivação da criança na aquisição da escrita: uma discussão... Letícia do Nascimento Schavarem • Pascoalina Bailon de Oliveira Saleh

Nesse sentido, de acordo com Aspilicueta (2014), a cópia pode ser interpretada como constitutiva da escrita, indicando a entrada do sujeito no texto próprio, ou pode apontar para um quadro sintomático na linguagem escrita, quando há uma permanência do sujeito na cópia do texto do Outro. Vale destacar que a cópia é entendida pela autora como repetição, pois o que o sujeito traz para seu texto são restos do texto do Outro, visto que essa repetição passa pela interpretação do sujeito.

No que se refere às rasuras, Pires (2015), apoiada na abordagem Interacionista de Claudia de Lemos, afirma que os acontecimentos envolvidos na heterogeneidade das rasuras, dos rearranjos textuais, das reformulações/autocorreções instanciam uma "cisão subjetiva: o impasse reside, no caso, na divisão do sujeito, na não coincidência entre aquele que escreve e aquele que se corrige" (PIRES, 2015 p. 17, ênfases da autora). Isso remete, ainda, à escuta/leitura para a própria fala/escrita, escuta esta que possibilita que o sujeito seja afetado pelo "imprevisível, pelo inesperado, pelo inaceitável que ocorre em sua produção" (PIRES, 2015, p. 18).

Portanto, o Interacionismo de Cláudia de Lemos, e seus desdobramentos pelos autores acima citados, contribuem para a análise e discussão propostas neste estudo, possibilitando olhar para a escrita das crianças e, em especial, para a presença de rasuras nas suas produções escritas, por meio dos movimentos subjetivos das crianças ao produzirem seus textos, visualizados a partir das filmagens dos encontros com as crianças, o que o distingue de pesquisas já realizadas sobre esse tema.

\section{Aspectos teórico-metodológicos}

Esta pesquisa se situa entre as áreas da Linguística e da Fonoaudiologia, que são aproximadas a partir da abordagem Interacionista de Cláudia de Lemos. Desse modo, segue uma diretriz qualitativa-descritiva, levando em conta os passos de Carvalho 
Movimentos de subjetivação da criança na aquisição da escrita: uma discussão... Letícia do Nascimento Schavarem • Pascoalina Bailon de Oliveira Saleh

(2005, 2006, 2013), para quem o olhar do investigador deve estar voltado para a resistência que a escrita da criança apresenta aos modelos teórico-empírico-metodológicos, suspendendo o saber prévio. Assim, a subjetividade do investigador se faz presente na escuta no momento em que é afetado pela resistência, que o surpreende, pois é inesperada.

O corpus é constituído por produções textuais de dois sujeitos, representados da seguinte forma: 1) Sujeito 1, A.L., 7 anos, $2^{\circ}$ ano, inserido em uma turma de contraturno, pois, de acordo com a escola, apresenta dificuldades na leitura e escrita; 2) Sujeito 2, A., 9 anos, $4^{a}$ série, também inserido em turma de contraturno, além de ser encaminhado à clínica fonoaudiológica, pela escola, também por causa de suas dificuldades de leitura e escrita. A produção textual desse segundo sujeito foi trazida de uma pesquisa anterior ${ }^{5}$, revisitada em função dos achados nas produções coletadas no presente estudo.

Nesse sentido, o encontro envolvido na coleta do dado referente ao Sujeito 1 foi realizado na própria escola no período do contraturno, tendo sido a proposta de escrita conduzida pela própria professora, que solicitou, a partir da leitura de uma história, que a criança desse continuidade à narrativa lida, como veremos mais adiante. Quanto ao Sujeito 2, a produção textual foi proposta e coletada pela pesquisadora fonoaudióloga durante encontros de escrita sem fins terapêuticos. A criança foi deixada livre para que escrevesse do modo que quisesse, também a partir da leitura de uma história completa.

Além das produções textuais, fizeram parte das análises as filmagens dos encontros, que foram transcritas, sendo destacados os principais aspectos do processo de produção dessas escritas. Quanto aos aspectos éticos, o presente estudo está de acordo com as normas e diretrizes de pesquisas com seres humanos, tendo sido aprovado pelo Comitê de Ética em Pesquisa envolvendo Seres

5 Referente ao Trabalho de Conclusão de Curso em Fonoaudiologia da primeira autora deste trabalho, intitulado "A inscrição da escrita na criança: relação do sujeito com as rasuras em textos copiados". Um artigo baseado no trabalho mencionado está disponível na Revista Distúrbios da Comunicação, cuja referência está citada acima. 
Movimentos de subjetivação da criança na aquisição da escrita: uma discussão... Letícia do Nascimento Schavarem • Pascoalina Bailon de Oliveira Saleh

Humanos da Universidade Estadual de Ponta Grossa (Parecer N ${ }^{\circ}$ 2.364.237). A seguir, analisamos e discutimos essas produções.

\section{Análise e discussão dos dados}

Retomando a perspectiva desenvolvida por De Lemos (2002), os processos de subjetivação possibilitam que um outro olhar seja estabelecido em relação às produções escritas, permitindo verificar o movimento da criança em diferentes posições na estrutura, estrutura esta relacionada à língua, ao sujeito que escreve e ao texto do Outro. Como já mencionado, a autora estabelece três posições do sujeito na aquisição da escrita: primeira posição, determinada por um sujeito alienado à fala/escrita do Outro; segunda posição, marcada por erros e acertos, entretanto, sem que o sujeito seja afetado pelo que diz/escreve e terceira posição, em que o sujeito é afetado pela sua fala/escrita, assim como pela fala/ escrita do Outro, aspecto que possibilita reformulações, pausas e hesitações. Ao resgatarmos as posições estabelecidas por De Lemos (2002) na aquisição da escrita, destacamos que, no decorrer de nossa análise, buscamos apontar aspectos referentes a essas posições.

A partir desse referencial, identificamos dois modos de relação da criança com a escrita e com o Outro na rasura: 1 - aquele em que o sujeito realiza um movimento de independência da escrita do Outro (Sujeito 1); 2 - aquele em que a criança se mostra relativamente dependente do texto escrito que vem do Outro (Sujeito 2). Consideramos como um movimento de dependência do texto do Outro quando há constante insistência em realizar cópias e tentativas de apresentar seu texto de forma idêntica ao do Outro, e o movimento de relativa independência quando essas tentativas não ocorrem, como veremos a seguir. 


\section{Rasuras e a relação de independência do texto escrito do outro}

Na produção textual realizada pelo Sujeito 1, notamos diferentes posições assumidas ao rasurar sua escrita, resultado de movimentos de estranhamento em relação a ela. Entretanto, há singularidades quanto ao que provoca esse estranhamento, podendo ser a sua própria escrita, a fala do Outro e/ou escrita do Outro.

Um dos aspectos importantes de ser retomado é que, durante a coleta e a análise dos dados, notamos que essa criança não se mostrou dependente do texto do Outro, ou seja, não realizou um movimento de cópia na tentativa de apresentar o seu texto igual ao que vem do Outro. Entendemos que esse movimento diz respeito à posição subjetiva de cada sujeito em relação à escrita, em que se fazem presentes marcas singulares das relações estabelecidas no processo em que se encontram, o de aquisição da escrita.

Seguimos, portanto, com a produção escrita relacionada à leitura da história $A$ casa sonolenta, base da produção textual de A.L., que será apresentada adiante. Destacamos que a proposta relacionada a esse dado envolveu não só A.L., mas todas as crianças inseridas na turma do contraturno, que também participaram do estudo. Entretanto, por limitações de espaço, selecionamos apenas a produção textual de A.L. para encaminhar nossa discussão no presente artigo.

A leitura dessa história foi feita de modo bastante interativo com as crianças, possibilitando que a acompanhassem no livro, observando também as ilustrações. Além disso, foram utilizados os personagens da história em forma de fantoches, juntamente com uma casinha. Em seguida, foi feita uma retomada da história, para que as crianças recontassem oralmente os trechos do texto lido. A partir disso, a professora fez a seguinte solicitação: 
Movimentos de subjetivação da criança na aquisição da escrita: uma discussão... Letícia do Nascimento Schavarem • Pascoalina Bailon de Oliveira Saleh

Prof.: se vocês fossem o autor da história, como vocês iam escrever uma história diferente, com uma casa acordada?... Eu queria que vocês dessem um final pra essa historinha ali, depois que eles acordaram, o que que aconteceu?

Ao iniciar a produção textual, uma criança pergunta se pode pular linha e a professora responde:

Prof.: Pode pular linha, pode pôr um título também... primeiro põe o título no meio da linha lá, vocês primeiro vão inventá o título ou deixá pra depois pôr o título, mais deixa um espaço lá pra inventá o título. Aí vocês vão fazê a continuação da história ou se vocês quiserem fazê uma nova história, vocês que vão sabê fazê... aí faz parágrafo, aí começa escreve o que vocês fariam...

Notamos que a solicitação da professora foi direcionada a uma atividade específica: inventar ou continuar a história com a casa acordada. Além disso, outras "exigências" foram feitas, como a presença de título na história.

No texto de A.L., apresentado a seguir, a primeira rasura observada é na data, na palavra "MAIO", em que há marcas de apagamento sob a letra ' $A$ ', em que, a partir das marcas deixadas no texto, notamos que havia sido escrito 'O'. Portanto, ocorreu uma reformulação de "MOIO" para "MAIO". 
Movimentos de subjetivação da criança na aquisição da escrita: uma discussão... Letícia do Nascimento Schavarem • Pascoalina Bailon de Oliveira Saleh

Figura 1: A.L.

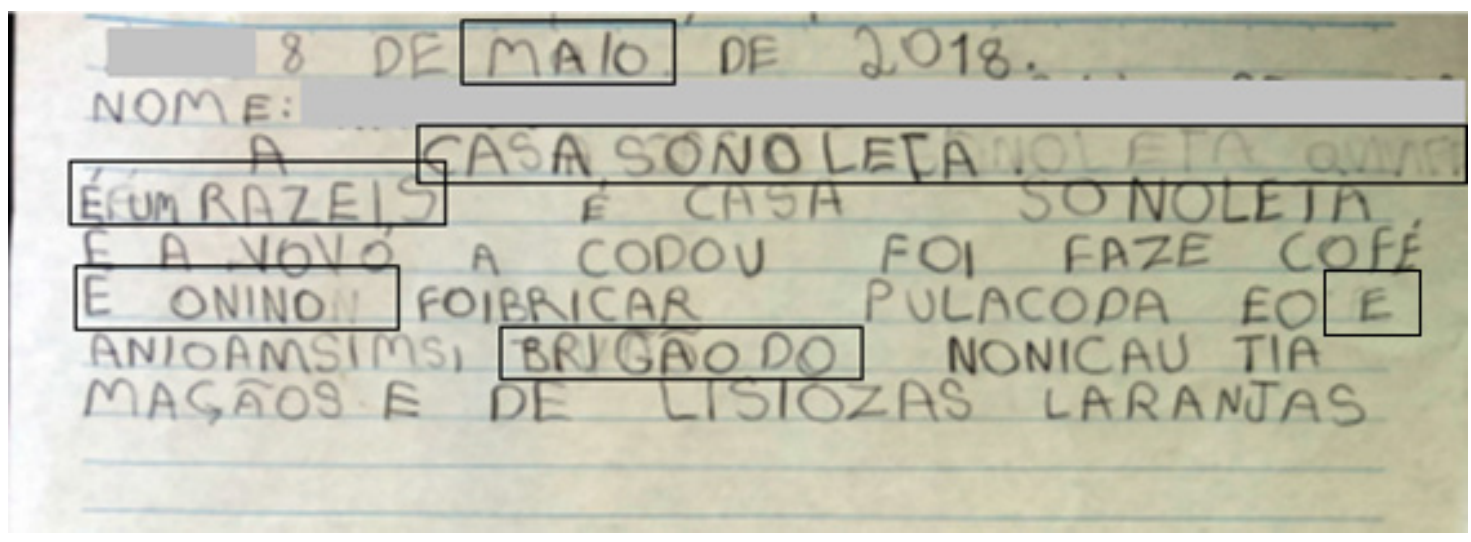

Fonte: Schavarem (2019, p. 64).

8 DE MAIO DE 2018.

NOME:

$$
\text { A CASA* SONOLETA* }
$$

É* UM* RAZEIS É CASA SONOLETA

EA VOVÓ A CODOU FOI FAZE COFÉ

É ONINO* FOIBRICAR PULACODA EO E*

ANIOAMSIMSI BRIGÃO DO* NONICAU TIA

MAÇÃOS E DE LISIOZAS LARANJAS

(Transcrição realizada pelas autoras).

No título, observamos marcas de apagamento, deixando rastros da escrita de "A CASA SONOLETA QVIVIFE". A criança apaga e escreve novamente apenas "A CASA SONOLETA", centralizando-o na folha.

Essa rasura ocorre a partir de um retorno de A.L. ao que havia escrito, retorno que pode estar relacionado tanto ao estranhamento com relação a sua própria escrita como também a uma escuta afetada pela fala da professora ao sugerir "põe o título no meio da linha lá" (cf. segmento 2), de modo a realizar esse movimento 
Movimentos de subjetivação da criança na aquisição da escrita: uma discussão... Letícia do Nascimento Schavarem • Pascoalina Bailon de Oliveira Saleh

de retorno, apagamento e centralização do título de sua história. Embora esse movimento possa ocorrer com qualquer criança em processo de aquisição, é importante destacar o possível efeito do lugar em que a criança em turma de contraturno é colocada pelo adulto/professor/escola na relação com a escrita, sendo lida como o sujeito que possui "dificuldades na aprendizagem", o que favorece a tentativa dela de se adequar àquilo que a escola espera e determina como correto/formal.

Outras marcas de rasuras são notadas em "É UM RAZEIS", onde observamos marcas de apagamento de um traçado inicial e da letra ' $E$ '. É interessante notar que a estrutura cristalizada "era uma vez" dá lugar a "É UM RAZEIS", havendo deslocamentos de letras nesse segmento. Nesse "erro" estão em jogo os processos metafóricos e metonímicos, ou seja, as possibilidades de cruzamentos da língua, que mudam totalmente a ordem dos elementos. Retomando esses processos, de acordo com De Lemos (2002), os movimentos neles implicados se referem à substituição de um elemento por outro (metáfora) e à combinação de um elemento com outro (metonímia) na cadeia.

Com base nas relações de seleção e combinação da linguística saussuriana, Jakobson (1975) parte da proposição de que essas relações são importantes para compreender a sistematicidade referente à fala/escrita de crianças em aquisição da linguagem. Portanto, diz respeito a "formas de organização da língua posta em funcionamento por um sujeito" (CAPRISTANO; CHACON, 2014, p. 2). Assim, os elementos ' $R$ ' e ' $A$ ' da palavra "ERA" se deslocam para "RAZEIS", em que são trazidos outros dois elementos: 'I' e 'S', que podem estar relacionados com a "pronúncia" de "VEIZ". Além disso, é feita uma inversão das letras ' $E$ ' e ' $Z$ ' da palavra "vez", em que 'E' vai para a parte final da palavra "RAZEIS" e a letra ' $Z$ ', para o meio. Dessa forma, o deslocamento desses elementos desfaz as relações metonímicas estabilizadas em "era uma vez", resultando em uma construção que não faz parte da língua, mas que não provoca efeitos em A.L. 
Movimentos de subjetivação da criança na aquisição da escrita: uma discussão... Letícia do Nascimento Schavarem • Pascoalina Bailon de Oliveira Saleh

Observamos, portanto, um movimento outro, que desloca o sujeito daquela insatisfação inicial, afetada pelo modo que coloca seu título, e passa a não ser afetado por "erros" presentes na sua escrita, o que diz de outra posição subjetiva em relação à escrita, a partir da qual não se "escuta" os "erros" e cruzamentos da língua. Embora haja presença de rasuras no início (letra 'É'), que é deslocada para a parte mais inicial da linha, não há "correções" nas palavras que seguem. Além disso, destacamos aí cruzamentos entre fala e escrita ${ }^{6}$ e salientamos que a fala produz efeitos na escrita, sendo possível haver cruzamentos entre esses dois modos de realização da linguagem, visto que estão submetidos às leis do funcionamento da língua.

Em “ONINO" há um 'N' apagado, havendo uma modificação de "ONINON" para "ONINO". Além disso, observamos, ao final da terceira linha, que a letra 'A' foi apagada, sendo substituída pela letra 'E', e sob "BRIGÃODO" é possível reconhecer os traços apagados de "TPVÃO" (escrita observada a partir das marcas deixadas no papel).

Diferentemente do que ocorre na rasura do título, as demais observadas no decorrer da sua escrita são decorrentes de um retorno de A.L. em seu texto, sendo afetada pelo seu próprio registro. Notamos que essas rasuras resultam em reformulações: ainda que a inserção no lugar do que foi apagado não remeta a um elemento da língua, houve um estranhamento no sujeito, que faz esse movimento de retorno.

Portanto, observamos dois movimentos envolvidos nas rasuras de um mesmo texto, de um mesmo sujeito: 1) Movimento em direção à rasura a partir de uma escuta afetada pelo dizer do Outro; 2) Movimento de afetação pelo seu próprio registro, realizando reformulações. Por outro lado, observamos segmentos e "erros" nessa produção que não provocam qualquer estranhamento em A.L.

\footnotetext{
6 Entretanto, desconsideramos a noção da escrita como representação da fala, noção esta, como aponta Pires (2015), que traz à tona o sujeito epistêmico, que possui controle de operações mentais e coloca a escrita como mera transcrição da oralidade, descartando as especificidades da escrita e da oralidade. Nesse sentido, partimos da ideia de que, apesar de ambas estarem submetidos ao funcionamento da língua e serem passíveis de cruzamentos entre elas, a escrita e a oralidade possuem um funcionamento diferente e, ainda, como aponta Marcolino e Catrini (2006, p. 104), "a heterogeneidade das manifestações da linguagem indica, por sua vez, que toda fala/escrita envolve, também, um modo particular de manifestação de um sujeito".
} 
Movimentos de subjetivação da criança na aquisição da escrita: uma discussão... Letícia do Nascimento Schavarem • Pascoalina Bailon de Oliveira Saleh

Destacamos, nesse ponto da discussão, um aspecto importante de ser frisado no que se refere às posições estabelecidas por De Lemos (2002): tanto os movimentos realizados por A.L. na sua produção textual como os que veremos posteriormente nos remetem ao fato de que as posições não se excluem entre si, pois, embora nessas ocorrências o sujeito não esteja em uma posição que transpareça uma relação mais estável com a língua, ele possui escuta e é atravessado/afetado pela fala/escrita do Outro.

\section{Rasuras e a relação de dependência do texto escrito do outro}

Na produção textual em que o sujeito realiza a cópia do texto do Outro, foram observados dois movimentos distintos em relação às rasuras: 1) Movimento de insatisfação do sujeito e dependência do texto do Outro; 2) Movimento de afetação do sujeito pelo próprio registro/escrito e retorno a ele. É importante destacar que consideramos que em ambos os movimentos ocorre o estranhamento, o que os diferencia é a escuta, afetada por um imaginário, de modos distintos.

Entendemos a insatisfação do sujeito com sua própria produção a partir do movimento que realiza ao tentar apresentar sua escrita igual àquela que vem do Outro, sendo afetado pela diferença que há entre seu texto e o texto do Outro. Nesse sentido, no que se refere ao primeiro movimento, a saber, de insatisfação e dependência, levantamos a hipótese de um imaginário afetado pelo discurso da escola sobre a criança, discurso que indica aquilo que esta não sabe fazer e precisa adequar para chegar ao que é "esperado".

Assim, vemos uma possibilidade de entender o lugar de fracasso escolar, pois no momento em que a escola insere o sujeito em turmas de contraturno e realiza encaminhamentos à clínica fonoaudiológica, por exemplo, aponta que há "algo fora do espe- 
Movimentos de subjetivação da criança na aquisição da escrita: uma discussão... Letícia do Nascimento Schavarem • Pascoalina Bailon de Oliveira Saleh

rado". O sujeito, então, se mantém dependente do texto do Outro na tentativa de atingir o modelo com o qual ele é constantemente comparado e, quando rasura, é pelo efeito de estranhamento diante do que não está "igual" ao "modelo".

Como efeito disso, parece haver a dependência constante, em que o sujeito tenta repetir o texto do Outro, porém, há deslizamentos e, quando o sujeito estranha, ele rasura para manter-se "colado" ao texto do Outro. Essa dependência pode dizer de uma necessidade de repetir, necessidade esta que, quando persiste, de acordo com Lier-DeVitto (2003), está relacionada às patologias da linguagem. O sintomático, para a autora, tem relação com o "não passar a outra coisa", ou seja, apresenta resistência a passar a outra posição na relação com a linguagem, demandando, por exemplo, o atendimento fonoaudiológico. Quanto ao segundo movimento, o estranhamento é efeito de um imaginário afetado por uma outra posição de escuta na linguagem, em que o sujeito é cindido. Assim, pode estar relacionado ao sujeito que estranha sua escrita a partir de seu próprio registro.

Veremos, mais adiante, que esses movimentos ocorrem em um mesmo texto, indicando um conflito dessa criança na aquisição da escrita e, ainda, que há possibilidades de mudanças, de modo que o sujeito não fica "preso" em uma única posição na linguagem, o que nos leva a questionar se seria demanda para o atendimento fonoaudiológico, levando em conta o que afirma Lier-De-Vitto em relação ao sintomático, destacado acima. Entretanto, não podemos avançar nessa questão, pois a caracterização de um quadro patológico de linguagem que demanda tal atendimento envolve a escuta para o histórico da criança e das relações desta com a escrita, informações que não foi possível explorar no presente estudo.

Situados os dois movimentos observados nessa produção textual, seguiremos apresentando cada um deles. Como mencionamos, o primeiro movimento se refere ao momento em que o sujeito realiza as rasuras apontando para uma preocupação em escrever igual ao texto do Outro, havendo, pois, insatisfação e de- 
Movimentos de subjetivação da criança na aquisição da escrita: uma discussão... Letícia do Nascimento Schavarem • Pascoalina Bailon de Oliveira Saleh

pendência. Isso pode ser observado no texto de A., destacado a seguir.

$\mathrm{Na}$ escrita de A., as rasuras aparecem no texto relacionado à história de João sem medo, narrativa lida em um dos encontros em que estavam presentes quatro crianças (C., V., A. e B.). Após a leitura, a pesquisadora solicita que escrevam sobre o que foi lido. A partir do fragmento (3), é possível verificar a solicitação da pesquisadora:

1. Pesq.: Agora eu vou dar um papel pra cada um e vocês vão escreve sobre a história

C: Da pra faze uma historinha e daí um desenho?

Pesq.: Pode ser historinha, desenho...

C: Sobre a tua historinha?

Pesq.: Sobre a historinha que acabei de ler, tá bom? Sobre a historinha. Pode contar do seu jeito, falar o que achou, de que parte mais gostou... Quem quiser ver a historinha tá aqui.

Embora seja essa a solicitação feita, a produção textual das crianças se direcionou para a cópia. A. pergunta à pesquisadora se "pode copiar igual o V." e ao ser orientado por ela a "fazer sem copiar", A. responde que "não consegue". Tanto ele como V. posicionam o livro ao lado e copiam, porém há bastante dispersão em A., o que faz com que ele acabe ficando atrasado na cópia em relação às outras crianças e, por isso, decida copiar do texto de B.

No decorrer das filmagens, observa-se que, ao longo de seu texto, A. retorna algumas vezes ao livro para escrever e para "corrigir" o que supostamente havia feito "errado". Ao pegar o livro, faz a leitura em voz alta de um trecho: "aqui, ó, certo dia...", retorna ao seu texto, apaga o que havia escrito e escreve novamente no lugar de "serto dia". Outro trecho em que ocorre rasura é em "o rei the permenteu", havendo marcas de apagamento na frase após ter retornado ao livro e ao seu texto. 
Movimentos de subjetivação da criança na aquisição da escrita: uma discussão... Letícia do Nascimento Schavarem • Pascoalina Bailon de Oliveira Saleh

Figura 2: A.
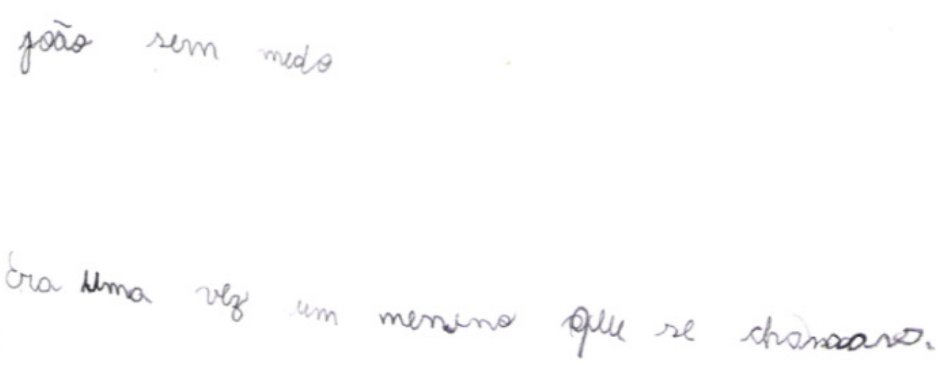

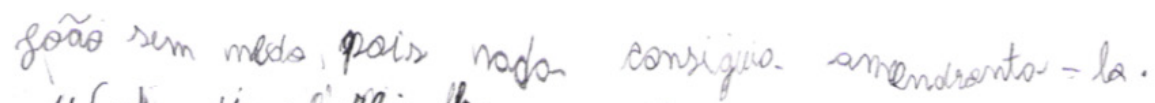

"Cuto dis, o'rei he permenter sequinte."

II Gôto, ise vol

Fonte: Schavarem (2019, p. 89).

João sem medo

Era uma vez um menino que* se chamava*

João sem medo, pois* nada conseguia amedrontá-lo.

“Certo* dia, o* rei* Ihe* permenteu* o seguinte:

"João, se você

(Transcrição realizada pelas autoras).

Nesses casos de rasuras, observa-se um movimento, bastante frequente, de retorno ao texto de apoio, o que indica que há uma dependência do sujeito em relação a esse texto e, portanto, uma tentativa de alcançar o modelo colocado pelo texto do Outro. Nos interrogamos se isso ocorre por efeito do discurso escolar, que marcaria esse sujeito na sua relação com a sua escrita, e o que notamos, com base nos dados analisados, é que o discurso da escola sobre o sujeito pode afetar seu imaginário, colocando-o em um lugar de dependência do texto que vem do Outro. Portanto, como afirmamos, interpretamos esse movimento realizado por essas crianças como resultante do efeito do discurso escolar sobre elas. 
Movimentos de subjetivação da criança na aquisição da escrita: uma discussão... Letícia do Nascimento Schavarem • Pascoalina Bailon de Oliveira Saleh

Ainda há, nesse texto de A., marcas de rasuras em outras palavras, que indicam outro movimento. Os retornos no próprio texto realizados por A. são observados: 1) na palavra "menino", em que há marcas de união entre "men" e "ino"; 2) na palavra "que", na qual reescreve a primeira letra por cima do círculo que havia feito; 3) na palavra "chamava", em que há marcas de rasuras nas letras 'M' e 'A'; 4) em "pois", onde há marcas na primeira letra; em "medo", na qual refaz a letra " $E$ " por cima do que havia feito; 5 ) em "amedronta-lo", em que retorna e acrescenta a letra 'E' novamente.

Essas últimas marcas de rasuras, observadas no texto de A., são realizadas sem que necessariamente a criança cheque o livro, pois ela estranha o que escreveu e retorna a sua escrita a partir da escuta/leitura e interpretação de seu próprio registro. Portanto, o que provoca a rasura é essa escuta/leitura, que marca a terceira posição em relação à linguagem. Dessa forma, não há nesse caso uma relação direta com a insatisfação e preocupação em estar igual ao modelo e sim com o efeito que tal escrita provocou no sujeito, havendo um estranhamento da própria escrita, o que diz de uma outra posição.

Vale destacar que, a partir da análise e discussão desses dados, é possível observar que ocorrem dois tipos de movimento em um mesmo sujeito e em um mesmo texto, o que diz de uma oscilação de movimentos e coexistência de posições do sujeito em sua relação com a linguagem. Portanto, as posições não são ocupadas teleologicamente: elas coexistem num mesmo tempo, num mesmo dado e, por vezes, podem se cruzar numa mesma ocorrência, ainda que às vezes não seja possível recuperar os movimentos nelas implicados.

\section{Considerações finais}

Assumindo a perspectiva desenvolvida por De Lemos e outros $(1992,1999,2002)$ em relação à aquisição da linguagem, nos pro- 
Movimentos de subjetivação da criança na aquisição da escrita: uma discussão... Letícia do Nascimento Schavarem • Pascoalina Bailon de Oliveira Saleh

pusemos a refletir acerca dos movimentos subjetivos dos sujeitos que se encontram nesse processo, visto que os processos de subjetivação, conforme a autora, permitem que um outro olhar seja estabelecido em relação às produções escritas, sendo possível verificar o movimento da criança em diferentes posições na estrutura, estrutura esta que implica a língua, o sujeito que escreve e o Outro.

As rasuras realizadas por essas crianças em suas produções dizem das suas relações com a escrita, do modo como cada uma é afetada de forma subjetiva e singular, seja pela sua escrita, seja pela fala/escrita do Outro. Dessa forma, notamos que há escuta nesses sujeitos que possibilita que interpretações sejam feitas, pois até mesmo aqueles que se mantêm na relação de dependência do texto do Outro são afetados pelas diferenças entre a sua escrita e a do Outro.

Além disso, levantamos hipóteses para alguns movimentos que esses sujeitos realizam e propusemos que o discurso escolar pode incidir sobre a relação da criança com a escrita, colocando-a em um lugar de tentativa de atingir o que a escola "espera" delas, uma vez que são vistas como crianças que possuem dificuldades na escrita, inseridas em turmas de contraturno e encaminhadas à clínica fonoaudiológica.

Observamos, inclusive, a subjetividade entre os sujeitos que se mantêm dependentes do texto do Outro e aqueles que não se mantêm, pois realizam rasuras em outra direção, a partir de diferentes posições. A criança que fica na relação de dependência do texto do Outro (Sujeito 2 ) é afetada pelas diferenças entre sua escrita e a do Outro e, na maioria das ocorrências, rasura na tentativa de aproximação ao Outro, ao mesmo tempo que é afetada pela sua própria escrita, indicando outra posição e, portanto, uma oscilação.

Quanto à criança que se mostra como relativamente independente da escrita do Outro (Sujeito 1), embora traga, em alguns momentos, fragmentos da fala do Outro para sua produção, é afetada 
Movimentos de subjetivação da criança na aquisição da escrita: uma discussão... Letícia do Nascimento Schavarem • Pascoalina Bailon de Oliveira Saleh

a partir de outras posições em relação a seu texto, seja pela interpretação ao seu próprio texto, seja pela escuta à fala do Outro ou pela interpretação do Outro em relação a sua escrita, provocando, portanto, efeitos diferentes nesta escrita, ainda que haja também uma oscilação de movimentos.

Buscamos olhar para essas crianças a partir da singularidade e subjetividade no processo em que se encontram, propondo que o professor inserido na alfabetização, bem como o fonoaudiólogo, mobilizado nos impasses da aquisição da escrita, possa considerar essas singularidades. Além disso, ao realizar uma pesquisa que envolve áreas como a Linguística e a Fonoaudiologia, estabelecemos aproximações entre essas áreas, colaborando, em especial, para estudos que envolvem a rasura, inaugurando um novo modo de olhar para esse aspecto.

No que se refere à Fonoaudiologia, podemos apontar para reflexões sobre os casos que chegam à clínica fonoaudiológica, contribuindo para que se pense, ainda que de modo limitado, quais são esses casos que demandam atendimentos, pois as crianças do estudo, por exemplo, se aproximam mais de uma posição de dificuldades com a escrita e apresentam oscilação de movimentos, indicando possibilidades de mudanças.

Acreditamos, portanto, que o estudo traz contribuições e levanta questões importantes, abrindo possibilidades para novas pesquisas em direção ao tema proposto e aos desdobramentos realizados, de modo a aprofundar ainda mais os aspectos aqui discutidos.

\section{Referências}

ANDRADE, Lourdes. Ouvir e escutar na constituição da clínica de linguagem. 2003, f. 143. Tese (Doutorado) - Pontifícia Universidade Católica de São Paulo, PUC, São Paulo, 2003.

ASPILICUETA, Patrícia. Movimento de subjetivação da criança na escrita de textos: entre o texto do outro e o texto próprio. 2014, f. 140. 
Movimentos de subjetivação da criança na aquisição da escrita: uma discussão... Letícia do Nascimento Schavarem • Pascoalina Bailon de Oliveira Saleh

Tese (Doutorado em Letras) - Universidade Federal do Paraná, Curitiba, 2014.

BRASIL. Ministério da Educação. Secretaria de Educação Básica.

Diretrizes Curriculares Nacionais Gerais da Educação Básica.

Diretoria de Currículos e Educação Integral. Brasília: MEC, SEB, DICEI, 2013. Disponível em: http://portal.mec.gov.br/index.php?option=com_docman\&view=download\&alias=15548-d-c-n-educacao-basica-nova-pdf\&Itemid=30192. Acesso em: 04 jun. 2019.

BORGES, Sônia Xavier Almeida. A aquisição da escrita como processo linguístico. In: LIER-DE VITTO Maria Francisca; ARANTES, Lourdes. (Orgs.). Aquisição, patologias e clínica de linguagem. São Paulo: EDUC-FAPESP, 2006. p. 149-159.

BORGES, Sônia. Psicanálise, linguística, linguisteria. São Paulo: Editora Escuta Ltda., 2010.

BORGES, S.; SILVA, D. G. M.; LOURES, J. M. T. Sobre alfabetização e psicanálise. Saarbrücken: Novas Edições Acadêmicas, 2017.

BOSCO, Zelma. A errância da letra: o nome próprio na escrita da criança. 2005, f. 291. Tese (Doutorado em Linguística) - Instituto de Estudos da Linguagem, UNICAMP, Campinas, 2005.

CAVALVANTE, Frazio Valdez Tenório. A "rasura escrita" em poemas inventados por alunos de $2^{\circ}$ e $3^{\circ}$ ano do ensino fundamental: análise de suas ocorrências. 2010, f. 130. Dissertação (Mestrado em Educação Brasileira) - Universidade Federal de Alagoas, Alagoas, 2010.

CAPRISTANO, Cristiane Carneiro. Mudanças na trajetória da criança em direção à palavra escrita. 2007, f. 253. Tese (Doutorado em Linguística Aplicada) - Instituto de Estudos da Linguagem Universidade Estadual de Campinas, Campinas, 2007.

CAPRISTANO, Cristiane Carneiro. Por uma concepção heterogênea da escrita que se produz e que se ensina na escola. Cadernos de Educação, FaE/PPGE/UFPel, Pelotas, n. 35, p.171-193, jan./abr., 2010. CAPRISTANO, Cristiane Carneiro. Um entre outros: a emergência da rasura na aquisição da escrita. Linguagem em (Dis)curso, Tubarão, SC, v. 13, n. 3, p. 667-694, set./dez. 2013. 
Movimentos de subjetivação da criança na aquisição da escrita: uma discussão... Letícia do Nascimento Schavarem • Pascoalina Bailon de Oliveira Saleh

CAPRISTANO, Cristiane Carneiro; CHACON, L. Relações metafóricas e metonímicas: notas sobre a "aquisição" da noção de palavra. In: TFOUNI, Leda; MARTHA, Diana Junkes Bueno. (Org.). 0 (in)esperado de Jakobson. Campinas-SP: Mercado de Letras, 2014. p. 197-212.

DE LEMOS, Claudia Thereza Guimarães. Los procesos metafóricos y metonímicos como mecanismos de cambio. Substratum, v. 1, n. 1, p. 121-135, 1992.

DE LEMOS, Claudia Thereza Guimarães. Língua e discurso na teorização sobre aquisição de linguagem. Letras de Hoje, Porto Alegre, v. 30, n. 4, p. 9-28, 1995.

DE LEMOS. Sobre o Interacionismo. Letras de Hoje, Porto Alegre, v. 34, n. 3, p. 11-16, 1999.

DE LEMOS. Das vicissitudes da fala da criança e de sua investigação. Cadernos de Estudos Linguísticos, Campinas, v. 42, p. 41-70, 2002. DE LEMOS. Uma crítica (radical) à noção de desenvolvimento na aquisição de linguagem. In: LIER-DE VITTO, Maria Francisca; ARANTES, Lourdes. (Org.). Aquisição, patologias e clínica de linguagem. São Paulo: EDUC-FAPESP, 2006. p. 21-32.

FERREIRO, Emília. Reflexões sobre alfabetização. São Paulo: Editora Cortez, 2001.

JAKOBSON. Roman. Dois aspectos da linguagem e dois tipos de afasia. In: Linguística e comunicação. São Paulo. Cultrix, 1975. p. 34-62 LACAN, Jacques. Seminário - livro 11: os quatro conceitos fundamentais da psicanálise, 1964. Rio de Janeiro: Jorge Zahar, 2008.

LIER-DEVITTO, Maria Francisca. Patologias da linguagem: subversão posta em ato. In: LEITE, N. (Org.). Corpolinguagem: gestos e afetos. Campinas: Mercado de Letras, 2003. p. 233-246.

LIER-DEVITTO, Maria Francisca; ANDRADE, Lourdes. Considerações sobre a interpretação de escritas sintomáticas de crianças. In: LIER-DE VITTO, Maria Francisca; ARANTES, Lourdes. (Orgs.). Faces da Escrita: Linguagem, Clínica, Escola. Campinas: Mercado de Letras, 2011. p. 95115. 
Movimentos de subjetivação da criança na aquisição da escrita: uma discussão... Letícia do Nascimento Schavarem • Pascoalina Bailon de Oliveira Saleh

MARCOLINO, Juliana; CATRINI, Melissa. O jogo entre falar/escrever/ler na clínica de linguagem com afásicos. Distúrbios da Comunicação, São Paulo, v. 18, n.1, p. 103-109, abr., 2006.

PIRES, Vera Lucia. Questões sobre a escrita em trabalhos afetados pela “ordem própria da língua". 2011, f. 112. Dissertação (Mestrado em Linguística Aplicada e Estudos da Linguagem) - Pontifícia Universidade Católica de São Paulo, São Paulo, 2011.

\section{PIRES, Vera Lucia. Pontos de conflito na relação criança-escrita} e seus efeitos heterogêneos: rasuras, reformulações, recomposições textuais. 2015, f. 113. Tese (Doutorado em Linguística Aplicada e Estudos da Linguagem) - Pontifícia Universidade Católica de São Paulo, 2015.

SAUSSURE, F. Curso de Linguística Geral. São Paulo: Ed. Cultrix, 1916/1993.

SCHAVAREM, Letícia do Nascimento. Movimentos de subjetivação da criança na aquisição da escrita: uma discussão voltada às rasuras. 2019, f. 130. Dissertação (Mestrado em Estudos da Linguagem) Universidade Estadual de Ponta Grossa, Ponta Grossa, 2019.

SCHAVAREM, Letícia do Nascimento; ASPILICUETA, Patricia; GALLI, Juliana Marcolino; CORDEIRO, Michelly Daiane de Souza Gaspar. A inscrição da escrita na criança: relação do sujeito com as rasuras em textos copiados. Distúrbios da Comunicação, São Paulo, v. 32, n.2, p. 181-195, jun., 2020. 